\title{
Comparison of MRI with $x$-ray in the evaluation of tuberculosis of spine
}

\author{
Bansal A. ${ }^{1}$, Kaur I. ${ }^{2}$, Kaur Mohi J. ${ }^{*}$, Garg Y. ${ }^{4}$ \\ DOI: https://doi.org/10.17511/ijmrr.2019.i05.06
}

${ }^{1}$ Aman Bansal, Junior Resident, Government Medical College, Patiala, Punjab, India.

2 Irwinjit Kaur, Junior Resident, Government Medical College, Patiala, Punjab, India.

3* Jaswinder Kaur Mohi, Associate Professor, Government Medical College, Patiala, Punjab, India.

${ }^{4}$ Yogesh Garg, Junior Resident, Government Medical College, Patiala, Punjab, India.

Introduction: MRI is the most valuable method for detecting early disease and is preferred technique to define the activity and extent of infection followed by $x$-ray. Aim: To evaluate MRI as a valuable noninvasive diagnostic tool in spinal tuberculosis and to correlate with plain radiograph for the early detection of spinal tuberculosis. Material and method: This cross-sectional study was carried out on 40 patients who were suspected as cases of spinal tuberculosis. Plain X-ray were done before the MRI examination. Results: The comparison of X-ray and MRI for evaluating spinal TB on the basis of end plate irregularity, thecal sac compression, cord compression and cord changes was statistically highly significant. It was statistically significant on the basis of Disk Space Narrowing/Disk Involvement, paravertebral Widening/Psoas abscess and Posterior Element Involvement. X-ray when compared to MRI was found to have a sensitivity of $48.72 \%$ and a specificity of $100 \%$ in detection of end plate irregularities, sensitivity of $89.47 \%$ and specificity of $100 \%$ in detection of vertebral height reduction, sensitivity of $78.79 \%$ and specificity of $100 \%$ in detection of disk Space narrowing / disk Involvement and sensitivity of $28.57 \%$ and specificity of $92.31 \%$ in detection of paravertebral widening/psoas abscess. Conclusion: MRI is a better and more Informative imaging modality in evaluation of patients of Pott's spine providing the diagnosis earlier than conventional methods.

Keywords: Tuberculosis, MRI, X ray, Disc Space, Cord compression, Spinal Tuberculosis

Corresponding Author

Jaswinder Kaur Mohi, Associate Professor, Government Medical College, Patiala, Punjab, India. Email: jmohi07@gmail.com
How to Cite this Article

To Browse

Bansal A, Kaur I, Mohi JK, Garg Y. Comparison of MRI with $x$-ray in the evaluation of tuberculosis of spine. Int J Med Res Rev. 2019;7(5):380-388.

Available From

https://ijmrr.medresearch.in/index.php/ijmrr/article/ view/1083

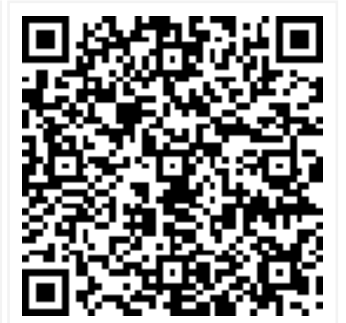

Review Round 2
2019-09-17
$\begin{gathered}\text { Ethical Approval } \\ \text { Yes }\end{gathered}$

Review Round 3

Accepted 2019-09-23

Plagiarism $\mathbf{X}$-checker $7 \%$

Note 


\section{Introduction}

Percival Pott was the first person to present the classic description of spinal tuberculosis in 1779; hence, spinal TB was called 'Pott's Disease [1]. Predisposing factors for tuberculosis include poverty, overcrowding, illiteracy, malnutrition, alcoholism, drug abuse, diabetes mellitus, immunosuppressive treatment and HIV infection. These are predisposing factors for spinal tuberculosis as well [2].

Spinal involvement is usually the result of hematogenous spread of $M$. tuberculosis into the dense vasculature of cancellous bone of the vertebral bodies. The primary infection site is either a pulmonary lesion or an infection of the genitourinary system [3-4]. Spread occurs either via the arterial or the venous route.

This vascular plexus facilitates hematogenous spread of the infection in the paradiscal regions. Batson's paravertebral venous plexus in the vertebra is a valve-less system that allows free flow of blood in both directions depending upon the pressure generated by the intra-abdominal and intrathoracic cavities following strenuous activities like coughing. In patients with noncontiguous vertebral tuberculosis, again it is the vertebral venous system that spreads the infection to multiple vertebrae [5].

Spinal tuberculosis is initially apparent in the anterior inferior portion of the vertebral body. Later on it spreads into the central part of the body or disk. Paradiskal, anterior and central lesions are the common types of vertebral involvement. A lack of proteolytic enzymes in mycobacterial infections (in comparison with pyogenic infections) has been suggested as the cause of the of the subligamentous spread of infection $[2,6]$.

In spinal tuberculosis, characteristically, there is destruction of the intervertebral disk space and the adjacent vertebral bodies, collapse of the spinal elements and anterior wedging leading to the characteristic angulation and gibbus (palpable deformity because of involvement of multiple vertebrae) formation.

The upper lumbar and lower thoracic spine are most frequently involved sites. More than one vertebra is typically affected, and the vertebral body is more frequently affected than the posterior arch [7]. Distortion of spinal column leads to spinal deformities [5]. Paraplegia is the most devastating complication of spinal tuberculosis.
Conventional X-rays are useful in diagnosis of spinal tuberculosis, but their main disadvantage is that more than $30 \%$ of bone has to be destroyed before a lesion can be seen on a plain radiograph, a process which takes nearly six months [8].

MRI because of the lack of ionizing radiation, high contrast resolution, multiplanar capability, ability to detect marrow infiltration and ease of assessment of extradural disease and status of spinal cord, has become the established optimal imaging technique for the evaluation and diagnosis of spinal infections and their sequelae [9]. MRI imaging is a very useful technique for differentiation of TB spondylitis from pyogenic spondylitis [10].

\section{Aims and Objectives}

- To demonstrate, analyze, and evaluate Magnetic Resonance Imaging as a valuable noninvasive diagnostic tool in spinal tuberculosis.

- To correlate with plain radiograph for the early detection of spinal tuberculosis.

\section{Materials and Methods}

Place of study: Department of Radiodiagnosis, Rajindra Hospital, Patiala

Duration: Nov 2016-Nov 2018 (2 years)

Type of study: Cross sectional

Sampling method: 40 patients in Department of Radio diagnosis, Government Medical College, Rajindra Hospital, Patiala which were referred to this department from the outpatient department and inpatients from the Department of orthopedics, general medicine, pulmonary medicine and pediatrics who were suspected as cases of spinal tuberculosis on the basis of their clinical presentation were included in the study.

\section{Inclusion criteria}

- Patients with or without neurological deficit at spinal level with strong clinical suspicion of spinal tuberculosis.

- All age groups

- Both sexes

\section{Exclusion criteria}

- Trauma patients.

- Uncooperative patients.

- Patients with metallic implants. 
- Patients with pacemaker/cochlear implant insitu.

- Patients with claustrophobia/ any other psychiatric abnormality.

Technique: Plain radiograph of spine of involved area was first done in all cases followed by evaluation on SIEMENS 1.5 TESLA MRI superconducting magnet.

Initially non contrast $\mathrm{T} 1$ weighted ( $T 1 \mathrm{~W}), \mathrm{T} 2$ weighted (T2W) and short tau inversion recovery (STIR) sequences in axial, sagittal and coronal planes of the involved spine were taken. Then postcontrast $\mathrm{T} 1$ sequence was obtained by using intravenous administration of gadodiamide (GdDTPA-BMA) of $0.1 \mathrm{mmol} / \mathrm{kg}$ doses, in axial, coronal and sagittal planes. The characteristic radiological features on plain radiograph and MRI along with response to treatment was considered diagnostic of Pott's spine; however wherever possible cytopathological or histopathological findings (specimen of decompression surgery or percutaneous aspiration/biopsy) were considered diagnostic of the condition.

\section{Results}

In our study age distribution ranged from 06- 70 years. Maximum patients belonged to the age group $31-40$ years $(35 \%)$ followed by $41-50$ years $(17.5$ $\%)$ then by $51-60$ years $(12.5 \%)$. The number of patients in other age groups was significantly less. The mean age of our study was 40 .

Level of lesion on MRI: In our study, lower thoracic $(32.50 \%)$ and lumbar $(40 \%)$ spine were most common sites of involvement accounting for $72.5 \%$ patients followed by upper thoracic spine $(25 \%)$. Cervical and sacral spine involvement was seen in only $15 \%$ patients.

Table-1: Level of lesion on MRI

\begin{tabular}{|l|l|l|}
\hline \multicolumn{1}{|c|}{ Level of Lesion } & No. of Patients & Percentage \\
\hline Cervical & 3 & 7.50 \\
\hline Upper Thoracic & 10 & 25 \\
\hline Lower Thoracic & 8 & 20 \\
\hline Lumbar & 16 & 40 \\
\hline Sacrum & 3 & 7.50 \\
\hline
\end{tabular}

T1WI and T2WI/STIR sequence signal intensities on MRI: In our study, most of the lesions were hypointense on $\mathrm{T} 1(87.5 \%)$ and all of these lesions were hyperintense on T2/STIR $(100 \%)$. These results were statistically highly significant.
Table-2: T1WI and T2WI/STIR sequence signal intensities on MRI

\begin{tabular}{|l|l|l|l|l|}
\hline \multirow{2}{*}{ Nature Signal } & \multicolumn{2}{c|}{ T1 Weight } & \multicolumn{2}{c|}{ T2 Weight/STIR } \\
\cline { 2 - 5 } & Patients & Percentage & Patients & Percentage \\
\hline Hypointense & 35 & 87.50 & 0 & 0 \\
\hline Isointense & 5 & 12.50 & 0 & 0 \\
\hline Hyperintense & 0 & 0 & 40 & 100 \\
\hline Total & 40 & 100 & 40 & 100 \\
\hline c2 & 58.72 & & \\
\hline p value & 0.001 & & \\
\hline Sign. & HS &
\end{tabular}

X-RAY findings: In our study, on X-ray, disk space narrowing was seen in $26(65 \%)$ patients, end plate irregularity in $19(47.5 \%)$ vertebral height reduction in $17(42.50 \%)$ patients. Paravertebral widening, deformity (kyphosis) and posterior element involvement was seen in $6(15 \%), 8(20 \%)$ and 4 $(10 \%)$ patients respectively.

\section{Table-3: X-Ray Findings}

\begin{tabular}{|l|l|l|}
\hline \multicolumn{1}{|c|}{ X-Ray Findings } & No. of Patients & Percentage \\
\hline End Plate Irregularity & 19 & 47.5 \\
\hline Vertebral Height Reduction on X-Ray & 17 & 42.50 \\
\hline Disk Space Narrowing on X-Ray & 26 & 65 \\
\hline Paravertebral Widening & 6 & 15 \\
\hline Deformity (Kyphosis) & 8 & 20 \\
\hline Posterior Element Involvement & 4 & 10 \\
\hline
\end{tabular}

Comparison of X-RAY and MRI: In our study, the comparison of $X$-ray and MRI for evaluating spinal TB on the basis of end plate irregularity, thecal sac compression, cord compression and cord changes was statistically highly significant. It was statistically significant on the basis of Disk Space Narrowing/Disk Involvement, paravertebral Widening/Psoas abscess and Posterior Element Involvement. However, the comparison on the basis of vertebral height and kyphotic deformity was statistically not significant. Hence it was concluded that overall the comparison of X-ray and MRI for evaluating spinal TB were highly significant.

\section{Sensitivity / specificity of X-RAY as compared} to MRI: The observations showed that X-ray had a sensitivity of $48.72 \%$ and specificity of $100 \%$ as compared to MRI in detection of end plate irregularity. X-ray had a sensitivity of $89.47 \%$ and specificity of $100 \%$ as compared to MRI in detection of vertebral height reduction. The X-ray when compared to MRI was found to have a sensitivity of $78.79 \%$ and a specificity of $100 \%$ in detection of disk Space narrowing / disk Involvement. 
Bansal A. et al: Comparison of MRI with X-ray in the evaluation

Table-4: Comparison of X-RAY and MRI

\begin{tabular}{|c|c|c|c|c|c|c|c|c|}
\hline & \multicolumn{2}{|c|}{ X-Ray } & \multicolumn{2}{|c|}{ MRI } & \multirow[t]{2}{*}{ Difference in Percentage } & \multirow[t]{2}{*}{$\mathbf{X} 2$} & \multirow[t]{2}{*}{$\mathrm{p}$ value } & \multirow[t]{2}{*}{ Sign. } \\
\hline & Patients & $\% a g e$ & Patients & $\%$ age & & & & \\
\hline End Plate Irregularity & 19 & 47.5 & 39 & 97.5 & 50 & 51.12 & 0.001 & HS \\
\hline Vertebral Height Reduction & 17 & 42.50 & 19 & 47.50 & 5 & 0.02 & 0.889 & NS \\
\hline Disk Space Narrowing/Disk Involvement & 26 & 65 & 33 & 82.50 & 17.50 & 8.01 & 0.040 & S \\
\hline Paravertebral Widening/Psoas Abscess & 6 & 15 & 14 & 35 & 20 & 16.45 & 0.002 & $\mathrm{~s}$ \\
\hline Deformity (Kyphosis) & 8 & 20 & 8 & 20 & 0 & 0.00 & 1.00 & NS \\
\hline Posterior Element Involvement & 4 & 10 & 8 & 20 & 10 & 9.38 & 0.003 & s \\
\hline Thecal Sac Compression & 0 & 0 & 40 & 100 & 100 & 24.86 & 0.001 & HS \\
\hline Cord Compression & 0 & 0 & 18 & 45 & 45 & 10.73 & 0.001 & HS \\
\hline Cord Changes & 0 & 0 & 6 & 15 & 15 & 16.39 & 0.001 & HS \\
\hline x2 & \multicolumn{4}{|l|}{45.00} & & & & \\
\hline $\mathrm{p}$ value & \multicolumn{4}{|l|}{0.001} & & & & \\
\hline Sign. & \multicolumn{2}{|l|}{$\mathrm{HS}$} & & & & & & \\
\hline
\end{tabular}

The X-ray when compared to MRI was found to have a sensitivity of $28.57 \%$ and a specificity of $92.31 \%$ in detection of paravertebral widening/psoas abscess.

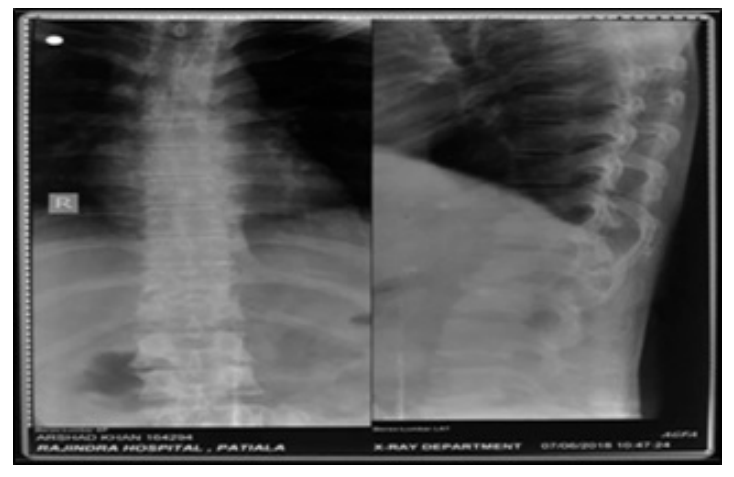

Figure -1: Plain $x$ - ray film -AP and Lateral view dorsal and lumbar spine -adjacent end plate irregularity at L1 and D12 vertebrae and reduced height of L1 vertebra seen. Disc space narrowing between L1 and D12 vertebra is seen.

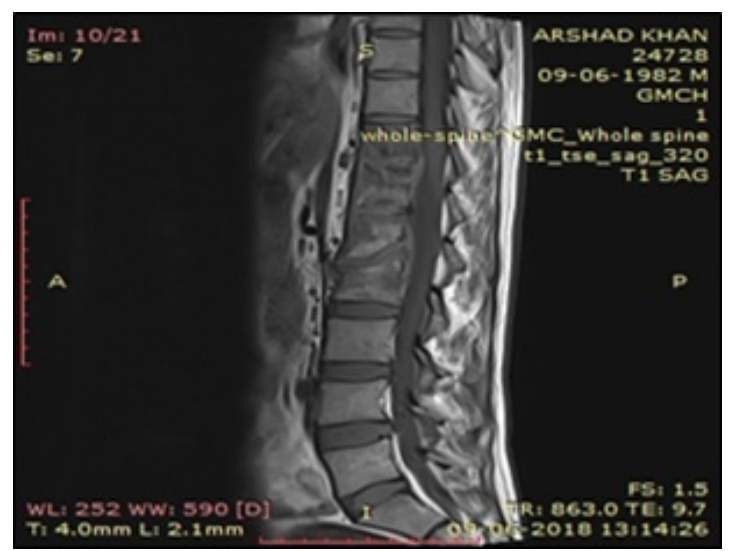

Figure-2: T1W SAG- Compression collapse of L1vertebra is seen with End plate irregularity and destruction of intervening disc between D11, D12,
L1 and L2 vertebrae and are hypointense in signal intensity. (same patient as in Figure 1).

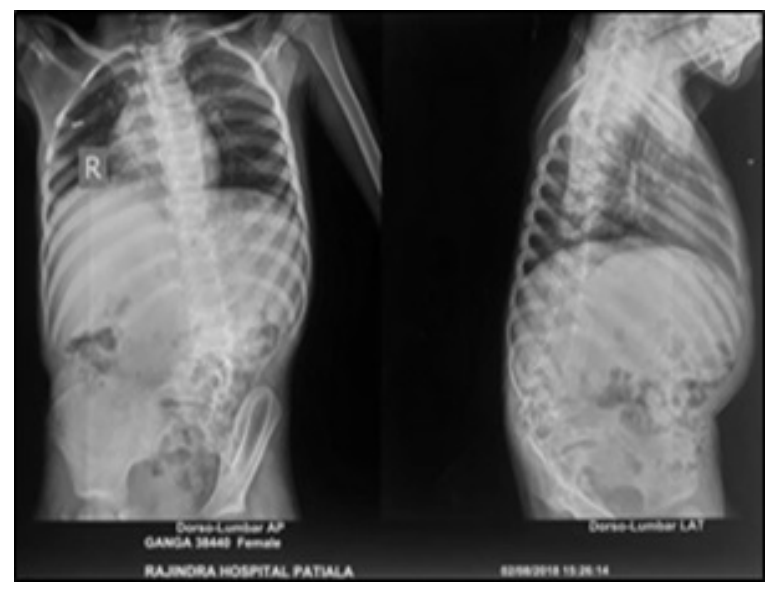

Figure-3: Plain $\mathrm{x}$ - ray film -AP and Lateral view of lumbo sacrum spine - shows end plate irregularity at L4 and L5 vertebrae and reduced height /compression-collapse of L5 vertebra seen. Disc space narrowing between L4 and L5 vertebra is also seen. Destruction of posterior element of lumbar spine and deformity/ kyphotic are seen.

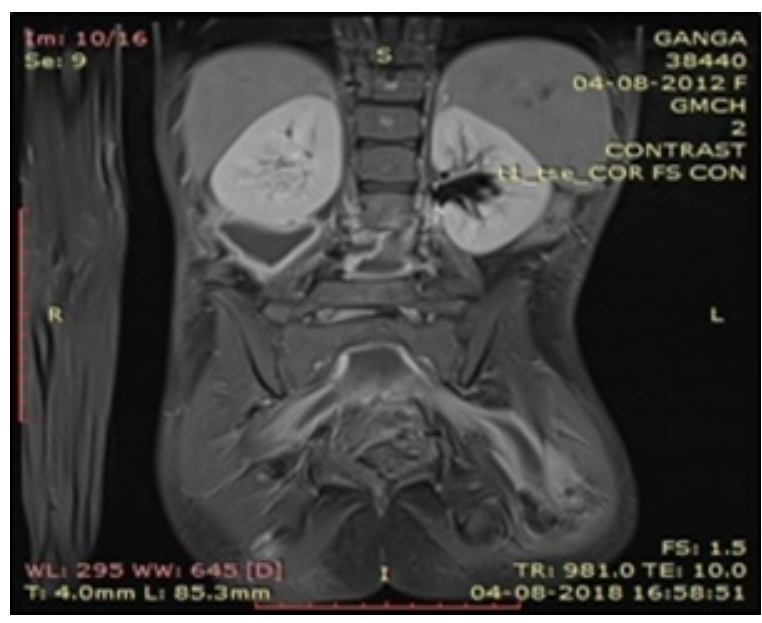


Figure-4: T2W axial- pre/paravertebral mass and epidural soft tissue component are seen. (same patient as in Figure 3).

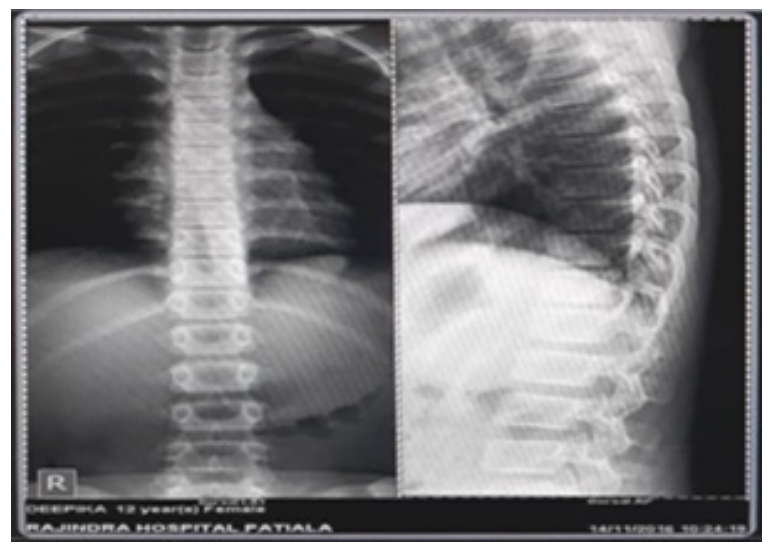

Figure-5: Plain $x$ ray- AP and Lateral view-no disc space narrowing and end plate irregularity seen.

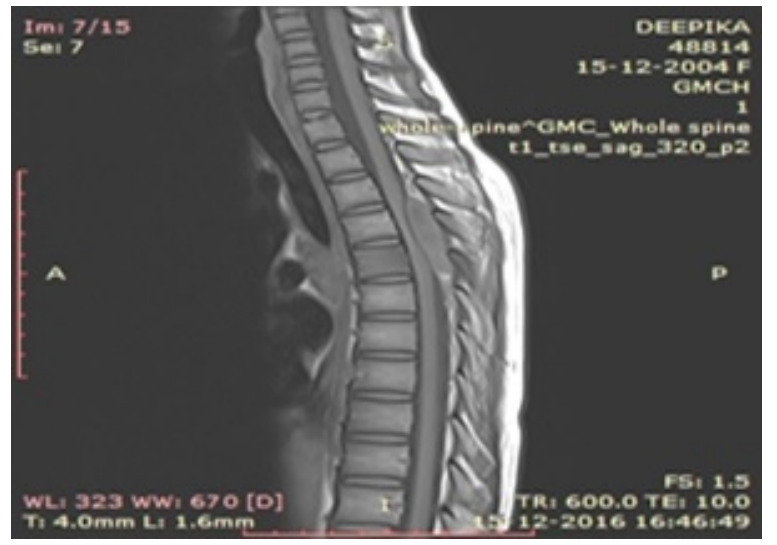

Figure-6: T1 SAG- D5 vertebra is hypointense in signal intensity. A large posterior epidural mass (yellow arrow), isointense in signal intensity is seen from D1 toD8 vertebral level causing anterior displacement and compression of spinal cord. (same patient as in Figure 5).

\section{Discussion}

A total of 40 patients with strong suspicion of spine tuberculosis were evaluated using MR imaging and $x$-ray. In our study age distribution ranged from 0670 years. Maximum patients belonged to the age group $31-40$ years (35\%) followed by $41-50$ years $(17.5 \%)$ then by $51-60$ years $(12.5 \%)$. The number of patients in other age groups was significantly less.

The mean age of our study was 40. Similar observation was made by Lifeso et al [11] where the mean age was 41.8 years.
Comparable result was seen in a study by Wang et al [12].

Similar finding was also stated by Sinan et al [13], who found that $43 \%$ cases in their study belonged to the age group of 30-49 years. In our study, lower thoracic and lumbar spine was most common site of involvement $(72.5 \%)$ followed by upper thoracic spine (25\%). Cervical and sacral spine involvement was seen in only $15 \%$ patients.

In a study conducted by Pallewatte et al [14] on 109 patients of Pott's spine lumber involvement was seen in $49.1 \%$ followed by thoracic in $38.8 \%$. The lower thoracic and upper lumbar levels had been reported to be the most common site of involvement in several previous studies by Owolabi et al [15] and Burrill et al [16].

In the present study, MRI detected altered signal intensity characteristics in all 40 patients out of which majority showed hypo-intense signal on T1 weighted imaging (35/40) and increased signal intensity on T2/STIR weighted imaging sequences (40/40) on MRI. These findings are similar to the ones brought out in the studies of Sharif [17] and Desai [18].

Dagirmanjian et al [19] found decreased vertebral body signal intensity on T1-WI in 39/41 (95\%) patients and increased vertebral body signal intensity on T2-WI in 22/39 (56\%) patients In our study, on MRI, end plate irregularity was seen in $39(97.5 \%)$ patients and absent in $1(2.5 \%)$ patient. This is in corroboration with other studies by Ansari et al [8] (2013). On MRI, vertebral height reduction was seen in $19(47.5 \%)$ patients and was normal in $21(52.5 \%)$ patients.

In a study conducted by Ansari et al [8] reduced disc height was noted in $19(63.3 \%)$ cases. Disc involvement was seen in $33(82.5 \%)$ patients and was absent in 17 (17.5\%) patients on MRI. Bajwa [20] found intervertebral disc space involvement in 95 percent of cases.

In our study, pre and paravertebral collection was seen in $29(72.5 \%)$ patients and was absent in 11 $(27.5 \%)$ patients. Osborn [21] stated that a paraspinal abscess was present in 55- 95\% of the cases. In our study, psoas abscess was present in $10(32.5 \%)$ patients on MRI. Similar result was found in a study conducted by Yasaratne et al [22] in which psoas abscess were seen in 7 cases out of 32 cases on MR. 
Comparison on X-RAY and MRI: In our study, the comparison of $\mathrm{X}$-ray and MRI for evaluating spinal TB on the basis of end plate irregularity, thecal sac compression, cord compression and cord changes was statistically highly significant.

It was statistically significant on the basis of Disk Space Narrowing/Disk Involvement, paravertebral Widening/ Psoas abscess and Posterior Element Involvement. However, the comparison on the basis of vertebral height and kyphotic deformity was statistically not significant.

Hence it was concluded that overall the comparison of X-ray and MRI for evaluating spinal TB was highly significant. Similar result was seen in study conducted by Kukreja et al [23] that imaging evaluation of patients with spinal TB showed that disk involvement, abscess and end plate irregularity were statistically better visualized on MRI as compared to X-ray.

Spinal canal narrowing, cord compression and compressive myelopathy could only be commented upon on MRI. Thecal sac indentation, spinal cord compromise/ canal stenosis and cord edema which are important findings for deciding patient management and future prognosis were picked up only on MRI. In the study conducted by Yasaratne et al [22] that the earliest feature of tubercular spondylitis was end plate involvement and oedema, which was detected on MRI whereas plain x-ray images were helpful in identifying fusiform paraspinal soft tissue swelling and vertebral collapse in advanced cases.

In the study conducted by Ansari et al [8] (2013) it was concluded that MRI was better than X-Rays to visualize intervertebral disk involvement.

Limitation: There was no information about the HIV status of the patients.

\section{Conclusion}

Both Plain X-Rays and MRI are important imaging modalities for diagnosis of spinal tuberculosis and are also useful to monitor the response of the patients to the treatment. Plain X-ray remains the primary and the first imaging modality to evaluate the disease. Plain radiography has few shortcomings in that radiographs generally remain normal in the early stages of the disease, hence by the time the disease is evident on plain X-Ray, the patient has already reached an advanced stage.
MRI has the advantages of improved contrast resolution for bone and soft tissues along with possibility of multiplanar imaging. It carries no risk of radiation which is particularly important in children and pregnant women.

It can even pick up clinically/X-ray occult multilevel involvement. However, MRI has the disadvantage of being a relatively expensive imaging modality which is particularly important in our country where quite a few patients belong to the low socio-economic status.

\section{What this study adds to existing knowledge?}

From the present study it can be inferred that MRI is a better and more Informative imaging modality in evaluation of patients of Pott's spine. It is the best diagnostic modality for spinal TB and is more sensitive than plain radiography.

It provides the diagnosis earlier than conventional methods, offering the benefits of earlier detection and treatment. MRI allows for rapid determination of the mechanism for neurologic compression and can distinguish between bone and soft tissue lesion. However, both $X$-rays and MRI have their own diagnostic importance, advantages and disadvantages and both are complementary to each other for evaluation of tuberculosis of spine.

\section{Author's contribution}

Dr. Aman Bansal: Concept, study design

Dr. Irwinjit Kaur: Data analysis, preparation of the manuscript

Dr. Jaswinder Kaur Mohi: Conduct of the study and data analysis

Dr. Yogesh Garg: Statistical analysis

\section{Reference}

01. Chauhan A, Gupta BB. Spinal tuberculosis. Indian AcadClin Med. 2007;8;110-4.

[Crossref]

02. McLain RF, Isada C. Spinal tuberculosis deserves a place on the radar screen. Cleve Clin J Med. 2004;71(7)543-549.

doi: $10.3949 /$ ccjm.71.7.537 [Crossref] 
03. Boachie-Adjei O, Squillante RG. Tuberculosis of the spine. Orthop Clin North Am. 1996;27(1)95103. [Crossref]

04. Schirmer P, Renault CA, Holodniy M. Is spinal tuberculosis contagious?. Int J Infect Dis. 2010;14(8)e659-66. doi: $10.1016 /$ j.ijid.2009.11.009 [Crossref]

05. Garg RK, Somvanshi DS. Spinal tuberculosis- a review. J Spinal Cord Med. 2011;34(5)440-454. doi: $10.1179 / 2045772311$ Y.0000000023 [Crossref]

06. Moorthy S, Prabhu NK. Spectrum of MR imaging findings in spinal tuberculosis. AJR Am J Roentgenol. 2002;179(4)979-983. doi: 10.2214/ajr.179.4.1790979 [Crossref]

07. Moon MS. Tuberculosis of the spineControversies and a new challenge. Spine (Phila Pa 1976). 1997;22(15)1791-1797. doi: 10.1097/00007632-199708010-00022 [Crossref]

08. Ansari S, Amanullah MF, Ahmad K, Rauniyar RK. Pott's Spine- Diagnostic Imaging Modalities and Technology Advancements. N Am J Med Sci. 2013;5(7)404-411.

doi: 10.4103/1947-2714.115775 [Crossref]

09. Sharma G, Ghode R. Tubercular SpondylitisProspective Comparative Imaging Analysis on Conventional Radiograph and MRI. Int J Anat, Radiol Surg. 2016;5(3)41-46.

doi: 10.7860/IJARS/2016/18136:2169 [Crossref]

10. Jain AK. Tuberculosis of the spine- a fresh look at an old disease. J Bone Joint Surg $\mathrm{Br}$. 2010;92(7)905-913.

doi: $10.1302 / 0301-620 \times .92 B 7.24668$ [Crossref]

11. Lifeso RM, Weaver $P$, Harder EH. Tuberculous spondylitis in adults. J Bone Joint Surg Am. 1985;67(9)1405-1413.

[Crossref]

12. Wang H, Li C, Wang J, Zhang Z, Zhou Y. Characteristics of patients with spinal tuberculosis- seven-year experience of a teaching hospital in Southwest China. Int Orthop. 2012;36(7)1429-1434.

doi: $\quad 10.1007 / \mathrm{s} 00264-012-1511-z \quad$ [Crossref]
13. Sinan $T$, Al-Khawari $H$, Ismail $M$, Ben-Nakhi $A$, Sheikh M. Spinal tuberculosis- CT and MRI feature. Ann Saudi Med. 2004;24(6)437-441.

doi: $\quad 10.5144 / 0256-4947.2004 .437 \quad$ [Crossref]

14. Pallewatte A $S$, Wickramasinghe NA. Magnetic resonance imaging findings of patients with suspected tuberculosis from a tertiary care centre in Sri Lanka. Ceylon Med J. $2016 ; 61(4) 185-188$.

doi: $10.4038 / \mathrm{cmj} . v 61 \mathrm{i} 4.8387$ [Crossref]

15. Owolabi LF, Nagoda MM, Samaila AA, Aliyu I. Spinal tuberculosis in adults- a study of 87 cases in Northwestern Nigeria. Neurol Asia. 2010;15(3)239-244.

[Crossref]

16. Burrill J, Williams CJ, Bain G, Conder G, Hine AL, Misra RR. Tuberculosis- a radiologic review. Radiograph. 2007;27(5)1255-1273.

doi: $10.1148 / \mathrm{rg} .275065176 \quad$ [Crossref]

17. Sharif HS. Role of $M R$ imaging in the management of spinal infections. AJR Am J Roentgenol. 1992;158(6)1333-1345.

doi: 10.2214/ajr.158.6.1590137 [Crossref]

18. Desai SS. Early diagnosis of spinal tuberculosis by MRI. J Bone Joint Surg Br. 1994;76(6)863869.

[Crossref]

19. Dagirmanjian A, Schils J, McHenry M, Modic MT. MR imaging of vertebral osteomyelitis revisited. AJR Am J Roentgenol. 1996;167(6)1539-1543. doi: 10.2214/ajr.167.6.8956593 [Crossref]

20. Bajwa GR. Evaluation of the role of MRI in spinal Tuberculosis- A study of 60 cases. Pak J Med Sci. 2009;25(6)944-947.

[Crossref]

21. Osborn AG. Nonneoplastic disorders of the spine and spinal cord, In- Diagnostic Neuroradiology. 1st edn, Elsevier. 2009;20;820-875.

[Crossref]

22. Yasaratne BM, Wijesinghe SN, Madegedara RM. Spinal tuberculosis- A study of the disease pattern, diagnosis and outcome of medical management in Sri Lanka. Indian J Tuberc. 2013;60;208-216.

[Crossref] 
23. Kukreja R, Mital M, Gupta PK. Evaluation of Spinal Tuberculosis by Plain X-Rays and Magnetic Resonance Imaging in a Tertiary Care Hospital in Northern India - A Prospective Study. Int J Contemp Med Res. 2018;5(2)B4-B9.

[Crossref] 